\title{
Entrepreneurial Skill Development through Aonla Processing in
}

\section{Punjab, India}

\author{
Manoj Kumar Mahawar ${ }^{1 *}$, Kirti Jalgaonkar ${ }^{1}$, Dattatreya Kadam $^{2} \&$ Prasad Chavan $^{1}$ \\ ${ }^{1}$ HCP Division, ICAR-Central Institute of Post-Harvest Engineering and Technology Abohar, Punjab, \\ India \\ ${ }^{2}$ ASEC Division, ICAR-Central Institute of Post-Harvest Engineering and Technology Ludhiana, \\ Punjab, India \\ *Manoj Kumar Mahawar, E-mail: manojmahawar362@gmail.com
}

Received: April 5, 2017

Accepted: April 25, 2017

Online Published: May 5, 2017

doi:10.22158/fsns.v1n1p23

URL: http://dx.doi.org/10.22158/fsns.v1n1p23

\begin{abstract}
Indian economy is predominantly dependent on agriculture and allied sectors as they are the important source of raw material and demand for many industrial products. As one among the allied sector, food processing sector is nowadays gaining attention amid entrepreneurs across the country. Famer's interest as an entrepreneur is constantly increasing in terms of investment which creates a promising atmosphere for affluent growth of food processing industry. Ministry of Food Processing Industries, Govt. of India is a wing which is actively engaged in promoting entrepreneurial activities in fruits and vegetables processing sector. However, there exists a definite demand to attract the small and marginal farmers to avail this entrepreneurship facility so that it can help in improving their livelihood and become a source of their family income. This particular case study is a representation of facilities availed by some entrepreneurs in ICAR-CIPHET Abohar for aonla processing. Such kind of information may become a source of encouragement for the farmers who are having a desire to promote themselves as farmer cum businessman.
\end{abstract}

\section{Keywords}

entrepreneurship, aonla, processing, pilot plant

\section{Introduction}

Although, India stands second in agricultural production but Indian agriculture is severely suffering with unacceptable level of wastages and failed to provide remunerative prices to farmers. This problem could be curtailed if appropriate strategies can be adopted for processing of agricultural commodities (especially fruits and vegetables) at their production catchments. In a study conducted by Nanda et al. (2012), the estimated losses are $5.8 \%$ to $18 \%$ for fruits and $7.5 \%$ to $13 \%$ for vegetables, respectively. 
The food processing sector surrounds with plentiful opportunities for the entrepreneurs, nevertheless the industry is forced to revamp the overall value and speed of its innovations. Significant progress of entrepreneurship in food processing segment will create work opportunities for rural youth and thereby augmenting the living standard of the people across the country (Negi, 2013).

Indian government under various schemes of MoFPI is encouraging the Entrepreneurial Development Programmes (EDP) which are intended to provide assistance to an individual in strengthening his entrepreneurial motive and in achieving skills and capabilities required for playing his entrepreneurial role effectively (Kumari, 2014). However, due to lack of skill, basic materials and inexperience, it might be difficult for new entrepreneur to launch and manage their enterprises. It is not only needed to motivate them but skilled them to manage their venture (Awasthi et al., 2006).

Processing of horticultural produce into value added products is emphasized by the Government of India by providing ample opportunities to the young potential entrepreneurs through EDP's and encourages them to establish their own processing industries. EDP helped the trainees in gaining basic knowledge of processing methodology, technological interventions and marketing of the product. Hands-on-training experience provides motivation and confidence to the trainees to initiate and manage a business venture. During such programs, trainees are also educated about the opportunities and financial assistance available for food processing units. The information to avail credit facilities from banks/financial institutions and assistance from the developmental organizations to procure equipments/raw material is also provided. Proper guidance towards establishment of marketing linkages for the developed products and the possible risk factors in running the units is also explained during the tenure of training (Anonymous, 2013).

Under Indian Council of Agricultural Research (ICAR), Central Institute of Post-Harvest Engineering \& Technology (CIPHET), Ludhiana is established with the vision of ensuring better income to farmers through post-harvest processing interventions. This can be achieved through value addition and by-product utilization of the agricultural produce (cereals, oilseeds, fruit and vegetables).

Indian Gooseberry or Aonla (Phyllanthus emblica L.) is one of the richest sources of vitamin C and is known for its medicinal values since long time. The crop is most ideal for arid regions of Punjab and Rajasthan like Abohar, Sriganganagar, etc. The main cultivated varieties of aonla are Kanchan (NA-4), Banarasi, Bansi Red, Desi, Krishna, Francis (Hathijool), Chakaiya, Pink tinged, NA-6, NA-7, NA-8, NA-9 and NA-10 (Rakesh et al., 2004). Due to its high astringency and low shelf life, the fruit is not popular as table fruit. The other methods of extending shelf life are by processing to murabba, pickle, juice syrup, squash and dehydrated powder (Kalra, 1988). As of now, the commercialization of aonla processing is limited and hence the growers are encouraged for entrepreneurship and ultimately towards establishment of small/medium/cottage level industries. But, for confidence boosting of small scale entrepreneurs and beginners to establish the industry on its own, it requires hands on experience so that they can adequately invest for procurement of machineries. The knowledge and practical exposure provided during the training will help in examining the entire facilities required to establish 
the plant according to their needs and available infrastructure (Kadam et al., 2012).

To enhance the processing perspectives of aonla as well as to improve the awareness of processing among the local farmers, Horticultural Crop Processing Division, ICAR-CIPHET Abohar is committed to organize need-based trainings for a period of 3-4 days. Interested participants from Punjab and Rajasthan attend such programs and gain requisite exposure under the guidance of scientific experts. A pilot plant facility is available at the division which is used for the processing operations to develop various valorized products. This study summarizes the overall evaluation of the processing and value addition of aonla using the existing pilot plant facility at ICAR-CIPHET Abohar.

\section{Materials and Methods}

An EDP on "Aonla Processing and Value addition" was organized from $29^{\text {th }}$ February to $2^{\text {nd }}$ March, 2016 at HCP division which was attended by 4 farmers from Punjab and Rajasthan. For processing operations, aonla fruits with similar maturation characteristics were procured from the farm of ICAR-CIPHET Abohar, Punjab, India. Dust and other impurities were removed by washing the fruits in tap water. The cleaned fruits were sorted and weighed as per the usage. The existing pilot scale facility was used for various processing operations (grading, shredding, pricking, juicing, etc.).

\subsection{Pilot Scale Processing Plant}

Existing pilot plant contains, fruit washing tank $(100 \mathrm{~kg} / \mathrm{h})$, fruit holding tank $(100 \mathrm{~kg} / \mathrm{h})$, aonla grader (4 grades), aonla shredder $(300 \mathrm{~kg} / \mathrm{h})$, aonla juice extractor $(55 \mathrm{lit} / \mathrm{h})$ and batch pasteurizer $(30 \mathrm{lit} / \mathrm{h})$. The view of the established pilot plant has been shown in Figure 1.

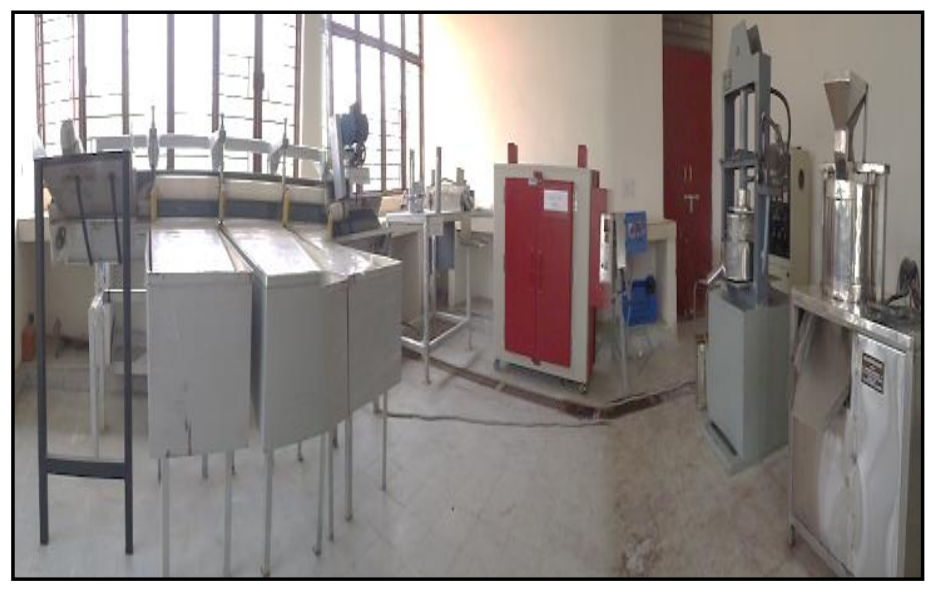

Figure 1. Pilot Plant Established at Agro Processing Unit

\subsection{Preparation of Aonla Juice}

Raw material of good quality aonla were sorted and washed with normal water. Cleaned fruits were weighed and crushed in aonla shredder in the batches of $5 \mathrm{~kg}$. Aonla shreds were collected from the two outlets while seeds were separated and collected at the outlet provided at bottom. After removal of 
the seeds, the recovery of the shred was $60 \%$ to $65 \%$. The collected shreds were subjected to pressing using hydraulic juice extractor (pressure range: $0-420 \mathrm{~kg} / \mathrm{cm}^{2}$ ) for collection of juice. Juice was then pasteurized at $82 \pm 4^{\circ} \mathrm{C}$ for $2 \mathrm{~min}$ and then allowed to cool to $55 \pm 2^{\circ} \mathrm{C}$. Potassium metabisulphate $(2 \mathrm{~g})$ was added to the juice as a preservative and the juice was packed in plastic bottles and stored in a cooling chamber at $12 \pm 2^{\circ} \mathrm{C}$. The remaining shreds were dried in tray dryer $\left(60 \pm 3^{\circ} \mathrm{C}\right)$ for $6-8$ hours and the dried product can be used to prepare mouth freshener, etc. The detailed procedure of juice preparation by means of flow chart is depicted in Figure 2.

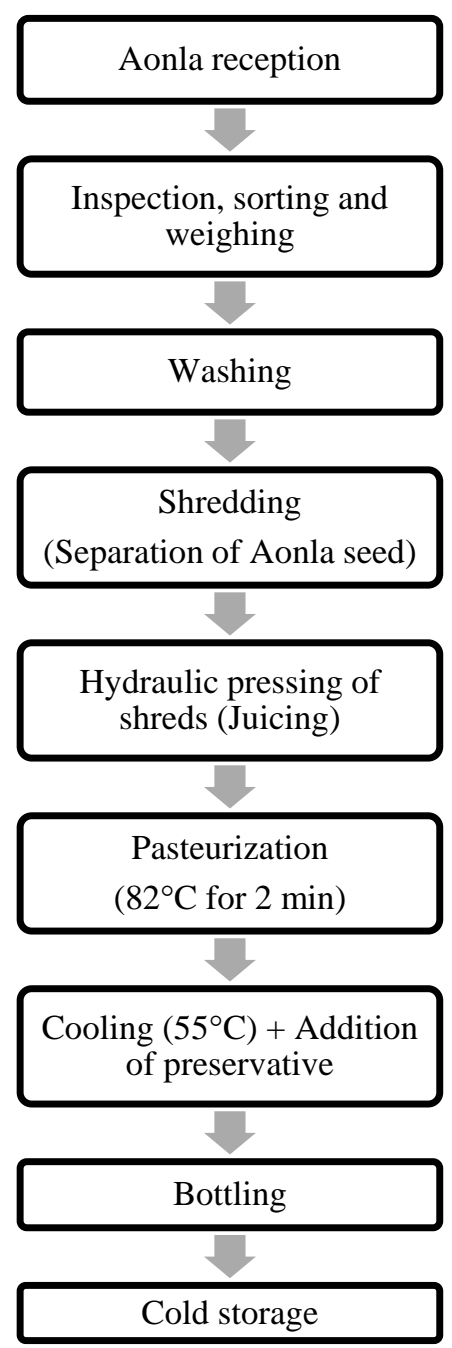

Figure 2. Process Flow Chart for Aonla Juice Preparation

\subsection{Determination of Physico-Chemical Properties}

Sphericity and colour of about 100 Aonla fruits were taken and average values are calculated. The obtained juice quality was determined in terms of Total Soluble Solids (TSS), titrable acidity and pH.

\subsection{Sphericity}

The major, minor and intermediate intercepts of the fruit were measured using digital vernier calliper 
(Make Mitutoyo with least count $0.01 \mathrm{~mm}$ ). Sphericity of the fruit was computed using following formula (Mohsenin, 1970; Mahawar et al., 2017):

$$
\text { Sphericity }=\frac{(a b c)^{1 / 3}}{a}
$$

Where, $\mathrm{a}=$ major intercept, $\mathrm{b}=$ intermediate intercept, $\mathrm{c}=$ minor intercept.

\subsection{Total Soluble Solids (TSS)}

The amount of sugar and soluble minerals present in fruits determines the TSS of any product. TSS of the juice was recorded using a digital refractometer (Make Atago, range $0-85^{\circ}$ Brix).

\subsection{Colour}

Colour of aonla fruits as well as aonla juice was recorded using Hunterlab colour analyzer (HunterLab MSEZ-4500L, Virginia, USA) and respective L, a, b values were obtained.

\subsection{Titrable Acidity (TA)}

It is a measure of the amount of acid present in a solution and was measured using the method described by (Ranganna, 2001).

$$
\mathrm{TA}(\%)=\frac{\text { Titre } \times \text { Equivalent weight of acid } \times 100}{\text { Volume of sample taken } \times 1000}
$$

\section{Results and Discussion}

\subsection{Physicochemical Properties}

Diameter of the aonla fruit was in the ranged from 42.37 to $45.71 \mathrm{~mm}$ whereas length was varied from 35.35 to $39.28 \mathrm{~mm}$. Sphericity of the fruit was varied from 0.92 to 0.95 which was in accordance. Weight of 10 aonla fruits was ranged from 225 to $235 \mathrm{gm}$. The fruits were of almost same colour with $\mathrm{L}^{*}$ value ranging from 54.60 to 64.06 , $\mathrm{a}^{*}$ value ranging from 23.27 to 30.52 and $\mathrm{b}^{*}$ value ranging from 23.68 to 33.93. The fruits were light greenish in colour with yellow shadow. Pulp of the fresh fruit contains 200 to $900 \mathrm{mg}$ of vitamin C as reported by several other workers (Kalra, 1988). Chemical properties of the aonla juice were tested to evaluate the quality of juice. Total soluble solidity of the juice was in the range of 15.7 to 17.3 whereas acidity and $\mathrm{pH}$ were in the range of 1.8 to 2.4 and 3.17 to 4.61 , respectively. The average values of the determined properties are tabulated in Table 1. 


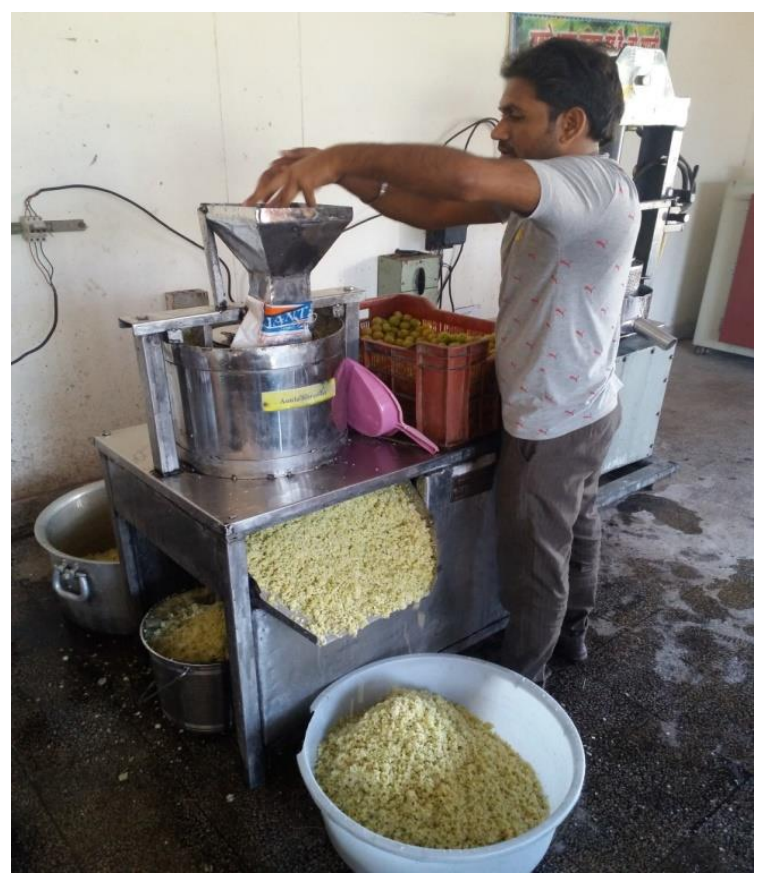

Figure 3. Aonla Shredding in Operation Performed by the Entrepreneur

Table 1. Physicochemical Properties of Aonla

\begin{tabular}{llllllllll}
\hline $\begin{array}{l}\text { Major } \\
\text { diameter }\end{array}$ & $\begin{array}{l}\text { Intermediate } \\
\text { diameter }\end{array}$ & $\begin{array}{l}\text { Minor } \\
\text { diameter }\end{array}$ & Sphericity & $\mathrm{L}$ & $\mathrm{a}$ & $\mathrm{b}$ & $\mathrm{TSS}$ & Acidity & $\mathrm{pH}$ \\
\hline $44.79 \pm$ & $44.11 \pm$ & $37.02 \pm$ & $0.93 \pm$ & $58.15 \pm$ & $25.92 \pm$ & $23.82 \pm$ & $16.74 \pm$ & $2.08 \pm$ & $3.85 \pm$ \\
1.09 & 1.61 & 1.23 & 0.01 & 3.35 & 2.15 & 3.59 & 0.61 & 0.25 & 0.66 \\
\hline
\end{tabular}

Note. Values given in the table are Mean \pm standard deviation.

\section{Economic Analysis}

One of the trained entrepreneurs has used the pilot plant facilities to process his raw material brought from the local area of Abohar. He used the facility in the last season for about 15 days on custom-hiring basis and some selected parameters were observed in order to obtain the detailed cost estimation of the overall juice extraction process. The information is tabulated in Table 2.

Table 2. Cost Analysis of Juice Preparation

\begin{tabular}{ll}
\hline Specification & Observation \\
\hline Total quantity of Aonla processed & 7 ton \\
Total quantity of juice recovered & 2250 litre \\
Cost of fresh Aonla & $13 \mathrm{Rs} / \mathrm{kg}$ \\
Number of working days & 15 \\
Working hours per day & $7-8$ \\
\hline
\end{tabular}




$\begin{array}{ll}\text { Juice recovery } & 32.14 \% \\ \text { Capacity of the shredder } & 300 \mathrm{~kg} / \mathrm{h} \\ \text { Capacity of juicer } & 55 \mathrm{lit} / \mathrm{h} \\ \text { Electricity consumed for shredding } & 1 \mathrm{~kW} / 40 \mathrm{~kg} \\ \text { Consumption of electricity for juicing } & 1 \mathrm{~kW} / 35 \mathrm{~kg} \\ \text { Labour engaged } & 7(5 \text { men, } 2 \text { women) } \\ \text { Labour charge } & 350 / \text { day }\end{array}$

\section{Conclusion}

Entrepreneurship development program has prominent role in entrepreneurial skill development, employment generation and it also provides opportunities to the small scale industries holders to improve their livelihood. The technologies developed by ICAR-CIPHET are well accepted and adopted by small and medium entrepreneurs in the nearby surroundings. To get larger impact of the technologies developed, there is urgent need to propagate the technologies in systematic manner, through imparting trainings; establishing faith among entrepreneurs towards viability of projects; establishing business units and making it profitable under the supervision and guidance of production/processing and marketing experts.

\section{References}

Anonymous. (2013). NMFPGOI. Guidelines for implementation of Human Resources Development scheme during the remainder of 12th Plan (2013-2017) under NMFP.

Arya, R. S. S., \& Moond, S. K. (2004). Processed products of aonla. Processed Food Industry, February, 20-23.

Awasthi, D., Jaggi, R., \& Padmanand, V. (2006). Manual for the entrepreneurs: Food processing Industry. A report of Ministry of Food Processing Industries, Government of India, New Delhi.

Goyal, R. K., Patil, R. T., Kingsly, A. R. P., Walia, H., \& Kumar, P. (2008). Status of post harvest technology of aonla in India. A review. American Journal of Food Technology, 3(1), 13-23.

Kadam, D. M., Kaushik, P., \& Kumar, R. (2012). Evaluation of guava products quality. International Journal of Food Science and Nutrition Engineering, 2(1), 7-11.

Kalra, C. L. (1988). The chemistry and technology of aonla: A resume. In Indian Food Packer (pp. 67-82).

Kalra, C. L. (1990). Role of blanching in vegetable processing. In Indian Food Packer (pp. 3-15).

Kumari, M. (2014). A study on entrepreneurship development process in India. Indian Journal of Research, 4(3), 51-53.

Mahawar, M. K., Jalgaonkar, K., Kumar, M., Meena, V. S., \& Bhushan, B. (2017). Determination of some physical properties of date palm fruits (cv. Khadrawy and medjool). Acta Agrophysica, 24(2), 
217-223.

Mohsenin, N. N. (1970). Physical Properties of plant and animal materials. Gordon and Breach Science Publishers, New York.

Nanda, S. K., Vishwakarma, R. K., Bathla, H. V. L., Rai, A., \& Chandra, P. (2012). Harvest and Post-Harvest Losses of Major Crop and Livestock Produce in India. Indian Council for Agricultural Research.

Negi. S. (2013). Food Processing Entrepreneurship for Rural Development: Drivers and Challenges. In IIM, SUSCON III Third International Conference on Sustainability: Ecology, Economy \& Ethics (pp. 186-197). New Delhi: Tata McGraw Hill Education. 